April - 2004

\title{
Tutoring Large Numbers: An unmet challenge
}

\author{
Helen Lentell and Jennifer O’Rourke \\ Commonwealth of Learning
}

Open and distance learning (ODL) is increasingly being regarded as a viable policy option for developing countries with limited educational resources for buildings, books and trained teachers, seeking to increase accessibility for large numbers of learners in education and training opportunities. Advocates of ODL as an appropriate solution to development issues tend to emphasise the hardware and software (curricula, materials and media of instruction and delivery, and especially ICTs) rather than the learning support needed (See, for example, World Bank, 2002).

In one sense this should not be surprising. As Lentell has noted, tutoring has never been at the forefront of mainstream writing on distance education, at least not until fairly recently (Lentell, 2003). However, whilst tutoring might not be central to the writing about ODL in the north, the practice is somewhat different. Tutoring tends to be the less visible element of ODL, but it is no less essential than good materials and effective administration. Distance education cannot exist without tutors who provide feedback and guidance to students. This point is well demonstrated by, for example, the array of institutional handbooks on tutoring produced by distance education universities. In practice, established distance education providers typically invest considerably in tutoring and other forms of learner support (Rumble, 1997). Moreover, and certainly among learner support professionals, there is an implicit "preferred" model. This model assumes a relatively low student-to-tutor ratio, with the tutor offering proactive individual guidance and feedback. Such a model, however, is not easily transferable to a situation where the reasons for adopting distance education are limited numbers of teachers and limited access to educational provision.

This situation suggests the need to research viable alternative learner support models developed to provide ongoing support and feedback to large groups of learners in proportion to limited numbers of tutors. This research is needed because:

1. Policy planners tend to be silent on tutoring and learner support where there are few teachers and limited resources

2. Models of tutoring and learner support based on low student-to-tutor ratios are not easily transferable to situations where there are limited educational resources

There are many unanswered questions about how best to achieve effective ODL provision when there are large numbers of learners in proportion to quite small numbers of qualified and trained tutors and/or educational counselors. Without a sustained examination of how to provide quality learner support in these situations, these ODL programmes risk high attrition rates and lost opportunities both for learners and their societies. 
This paper presents a research agenda, rather than research findings on learner-support in situations where tutor-student ratios are high. We argue that there is a need to rethink some underlying assumptions about tutoring that are implicit in many established models of ODL that assume relatively small tutor-to-student ratios. Because it is unrealistic to assume that there will be small student-to-tutor ratios in many contexts, especially in the developing world, we suggest the need to research viable alternative learner support models that will provide ongoing support and feedback to large groups of learners. If ODL cannot meet the needs of large cohorts of learners, then it is in danger of becoming yet another exported Western approach that consumes large amounts of resource at the initiation stage, yet fails to be sustainable in the long-run.

\section{Background}

Most models of open and distance learning that have evolved over the past three decades have assumed consistent and personal interaction between learners and a tutor. This interaction provides motivation, guidance, feedback, assessment, and support for learners. But the frequency and level of interaction assumed by this model is feasible only if there is a manageable group of learners assigned to each tutor. Definitions of "manageable" vary among providers, but the guiding principle is usually stated in terms of response times: for example, that tutors should be able to provide feedback to learners within 10 days to two weeks of receiving their assignment. Online tuition has changed expectations for a response to two or three days.

The concept of personalised tutoring evolved out of two parallel approaches that the UK Open University adopted and adapted for open and distance learning. One is based on the Oxbridge concept of the tutorial in which a tutor with subject expertise meets with a small number of students and comments on each individual learner's work (Mills, 1999). The other is the concept of a counsellor, who "would not necessarily have expert knowledge of every specific element of the course, but would be concerned with the educational process in which the student was engaged” (Sewart, n.d.). In other words, while the tutor was mostly focused on the learner's grasp of the subject, the counsellor was most concerned about developing the learner's skills in learning. Currently, tutors handle both roles in many open and distance learning programmes. However, the concept of a counsellor who is not a subject expert offers potential models and methods for supporting large numbers of distance learners. We will return to this idea later in the article.

More recent developments in e-learning assume a greater level of interaction among learners, and more frequent and timely interaction between learners and a tutor than in print-based courses. Because this type of learning requires much more input from tutors than previous forms of distance education, reports on e-learning experience often indicate a ratio of no more 20 to 30 learners per tutor (Conrad, 2002; Mason, 1999; Goodfellow, 1999). E-learning has been typically used in graduate programmes or in specialised fields which benefit from collaborative learning. The tutor's role includes moderating online discussions, facilitating group learning, problem solving, and guidance. However, there have not yet been practical proposals concerning "scaling up" e-learning so that it can manage even current learner-tutor ratios handled by conventional distance learning, much less the usually large learner numbers facing open and distance learning providers in many parts of Africa and Asia.

In the past few decades, proponents of distance education have made great efforts to counteract the lingering image of correspondence schools that enrolled huge numbers, but provided minimal or no support and offered successful outcomes to even fewer. In contrast, distance educators emphasised the "continuity of concern" (Sewart, n.d.) offered by personalised attention from 
individual tutors. The UKOU's model of distance education stressed the value of local tutorials and personal contact with a tutor, even as numbers expanded dramatically. The UKOU's own research, however, indicates that only a proportion of learners actually take up the offer of individualised help (Mason, 2003). Many learner support systems are predicated on the assumption that not everyone will use them, which means that support staff would be overwhelmed if all enrolled learners actually took advantage of all the tutorial and support services on offer. Seasoned distance educators suggest that rather than offering one-size-fits-all support, providing customised levels of support for different learners in different contexts may be more effective and efficient (Mason, 2003; Mills, 2003).

Following the success of the OU model, many other ODL providers that evolved have maintained the central importance of individualised tutoring. Research has provided evidence of the effectiveness of this approach (Gibbs and Simpson, 2002). Having made great strides in developing successful approaches to ODL predicated upon the strengths of personalised support, it is understandable that distance educators may be reluctant to reconsider one of the basic tenets of their practice.

The issue, however, is not whether or not there should be personalised tutoring in ODL, but what can be learned from the success of personalised tutoring that might inform us of the processes that may be transferable to other situations. How can the effective elements of personalised tutoring be brought into situations where there are large numbers of learners? Can we rethink new models of ODL learning support that address these situations of large numbers and limited resources without introducing a "deficit perspective" - i.e., that these alternatives are second best. What are the strengths of these approaches with large student numbers that can be used to create alternative models of supportive learning situations?

Rather than start from the judgmental position that there should not be large numbers of learners per tutor in ODL systems, we will expand the discussion to consider how to address the reality of large numbers. A distance methodology has to accommodate large numbers if it is to be of any practical value in most educational and training contexts in Africa, Asia, and the Caribbean. Moreover, providing support to large numbers of learners is not just a fact of life in large, single mode distance education institutions, but on many programmes offered by traditional face-to-face institutions and non-governmental organizations: for example, programmes for pupils in secondary schools, training teachers, and healthcare workers.

When the following scenarios were presented at the Cambridge Conference in 2003, we invited colleagues from Africa, Europe, and North America to consider how to meet learners' needs appropriately. All but one of these scenarios were drawn from ODL situations with large numbers of learners; the non-ODL example was about the possibility of ODL methodology enabling teachers to manage large classes in conventional settings. Some scenarios were drawn from technology-rich contexts and some in situations where resources are limited. A summary of each scenario is provided below; readers can click on the title to read the whole scenario and consider the questions posed.

1. Tutoring large numbers of students older than 16 years of age who were preparing for advanced school leaving exams in a conventional tertiary college in the Caribbean. See Appendix $\underline{1 .}$

2. Strengthening tutor support at a local study centre that serves students enrolled at a new open university in Africa. See Appendix 2. 
3. Developing tutor support systems for a Care in the Community programme offered to learners living on widely dispersed small islands in the South Pacific. See Appendix 3.

4. Scaling-up tutorial support for a worldwide environmental education programme for professionals. See Appendix 4.

5. Adopting a more effective tutorial strategy for learners in an unpaced programme leading to a law degree. See appendix 5.

6. Developing a more efficient tutorial approach for participants preparing for accountancy accreditation. See Appendix 6.

7. Planning appropriate support and assessment for infection control training for medical staff. See Appendix 7.

8. Strengthening support for a work-based skills training programme in the leather industry. See Appendix 8.

Although participants found the issues challenging, they recognized the scenarios as remarkably similar to the real issues they face daily as distance educators. Their proposed strategies included:

- Decentralising learner support so that it is as localised as possible; making use of local resources such as experienced teachers or healthcare professionals, who could be mentors or resource people for learners

- Helping learner groups to become self-sustaining, by providing resource materials and guides for group study

- Developing self-assessment tools for groups of learners

- $\quad$ Supporting discussions (online or face-to-face) that build communities of practice

- Enabling collaboration among professionals

Participants also agreed that learner support is essential for most learners, and it can be fostered in different ways:

- $\quad$ Supporting self-directed learner groups

- Supporting local people who can provide mentoring

- linking learning and the workplace so that learners can apply their learning in practice, with the guidance of more experienced staff

\section{Supporting Social Learning}

One of the prevailing perspectives on learning in many Western educational institutions is that learning is regarded as a personal acquisition achieved through individual effort, to obtain personal qualifications and recognition. Individualised tutoring is consistent with this perspective. This dominant model in education is not necessarily representative of the many cultures within western societies, and it is not necessarily appropriate for non-western societies either. North 
American aboriginal learners, for example, typically value a more collective approach (Spronk, 1995). Facey (2001) comments:

Although generalisations are necessarily limited, there is a wealth of evidence in anthropology to show that peoples whose societies forefront kinship relationships do have a more group - than individual - oriented identity ... This means in practice that the student weighs his or her community's needs - for example, needing certain categories of native workers such as nurses, foresters or social workers - alongside his or her personal interests in taking certain programs or training. Similarly, personal educational priorities appear to be always subjugated to family priorities, matters such as illness or a funeral taking precedence over attending class, meeting an assignment deadline, and so forth.

There may be room to develop alternative models for providing learner support that recognise and build on the strength of the learners' social context, particularly in contexts where learning is regarded as a social activity, achieved through collaboration, which benefits society as much as it benefits the individual. If social models of learner support were developed as valid in their own right, rather than as low-cost or high-volume alternatives to the individual support model, open and distance learning practice could become much more responsive to the needs of learners in a broad range of situations. Rather than serving as a pro-tem answer to a critical shortage of educated people, to be replaced with better alternatives when the crisis abates, ODL could become the best option for responsive education.

Here are two examples of support that may address the needs of larger groups of learners, but there are many more possibilities:

\section{Self-Directed Study Groups}

Chadibe (2002) describes how participation in self-directed study groups enables South African learners to make better use of distance courses and tutorials:

. . . study groups are set up, usually by learners themselves, in conjunction with tutorials, so that tutorials enable study groups and also keep them on track. . . The reasons respondents gave for participating in a study group are themselves examples of the development of 'learner autonomy' among them: “. . . a study group gives one more insight and enables you to participate. What you have discussed in a group once, you will never forget. If you agree to come to the group knowing something about the chapter you agreed to prepare for that meeting you are forced to do so. It is usually unacceptable if you keep coming up with apologies caused by lack of prior preparations. It benefits us, as we know that each one of us has to prepare before hand. It also encourages us to study hard. We build confidence in each other; even introverts become extroverts because each one is given a chance to say something. Each one chooses the chapter she wishes to prepare for the next study group meeting; especially a chapter she wants to understand better (Chadibe, 2002, www.col.org).

Chadibe points out that, given the value of these groups, there should be more support provided for them, especially from local and regional study centres. She also recommends that providers with limited resources should concentrate on providing tutorial support for first-year learners. 
... there is a need for the learning centre to advise the new learners thoroughly so that they can begin their studies by taking the courses that usually have tutorials their first year and then proceed to the less popular courses in their second year of studying. This would be in keeping with the principle of incremental 'enskilling' the learner in the first year with, for example, study skills, development of reading and writing skills, and participation in collaborative or peer group studying. This would empower the learners to develop into critical and independent learners (Chadibe, 2002, www.col.org).

Bertram's research on self-directed study groups examines how learning takes place within them, and observes that learners "are adopting a communal approach to learning" by sharing responsibility for reading and explaining the course materials. Groups with limited university experience had difficulties in going beyond surface learning approaches and in developing individual learning skills, although the groups provided a great deal of motivation and continuity. Provisions to develop generic academic skills in writing, developing a thesis, and so on, could complement the affective support offered by self-directed study groups (Bertram, 2003).

\section{Reviving the Concept of Learner-Counsellors}

Reviving the concept of the counsellor might also help to address the needs of large numbers of learners. As Beevers, the UKOU's first Director of Studies observed: “Adult education experience suggests that at least 50 per cent of a given student's needs are not strictly related to the subject at hand. That is not to say that his needs are solely psychological and unconnected with the content of study; the help s/he needs is of an educational kind, even of an academic kind, but not strictly subject-based" (as quoted in Sewart, n.d.). Sewart expands on this idea: "The counsellor . . . would be concerned with the educational process in which the student was engaged. Conceived of in this fashion, the counsellor was much more likely be available on a local basis" (Sewart, n.d.). Some recent ODL programmes build in a role for a mentor, especially in workplace and professional programs (Leach, 1999). There is potential to expand and define other roles for local support people who can help learners build confidence, enhance their learning skills, and maintain a commitment to their studies. As Beevers and Sewart point out, this kind of support does not necessarily require subject-matter expertise, so it should be possible to make it available on a local or community basis (Seward, n.d.).

\section{Managing Expanded Learner Support}

Implementing effective learning support is also a management challenge. One large distance education provider, China Central Radio and TV University (CCRTVU), which has served millions of learners since 1979, is now moving into a multi-tier system for strengthening provision of learner support ( $\mathrm{Li}$ Yawan and $\mathrm{Li}$ Linshu, 2003). In addition to its existing cooperative arrangements with provincial universities, branch schools, and local teaching centres, CCRTVU is in the process of establishing a national public support system platform, providing online access to learning resources, individual experts, and support for study groups. It is expected that within three years, 1000 study centers will be established that can be used for learner support by any distance education providers. This initiative is a response to an identified need for strengthened support for distance learners. 


\section{Conclusion}

In writing this article, the authors have tried to take into account the real context for ODL in many parts of Africa, Asia, and the Caribbean, but it is inevitably framed by our underpinning assumptions about tutoring in ODL. We hope that educators who serve large numbers of learners will enter into the discussion and share their insights and perspectives in IRRODL.

At this stage, we have more questions than answers. However, we think it is worth posing questions about our oftentimes 'unexamined' assumptions, even those cherished beliefs on the role of tutors in learner support. Asking such questions is an important step, given that there has been a reluctance to ask: "How can we tutor large numbers?" This reluctance is rooted in a dominant viewpoint that distance education must have tutors to provide personal attention to relatively small groups of learners. We know there are many ways of learning and many ways of supporting learning in both conventional and distance settings. Perhaps it is time to ask ourselves: Is the precept about individualized tutor support for small numbers yet another example of a Western world approach dictating 'the right way' to do something, despite its impracticality for the majority world? We suggest it is time to start researching other models and methods of providing learner support in situations of large student numbers. We believe that ignoring this issue will lead to the failure of ODL to deliver on its promise: increasing accessibility for large numbers of learners to education and training opportunities.

\section{References}

Bertram, C. (2003). Exploring informal student study groups. In A. Tait and R. Mills (Eds.) Rethinking Learner Support in Distance Education: Change and Continuity in an International Context. London: Routledge.

Centre for Advanced Learning Technologies (n.d.). Centre for Advance Learning Technologies website. Retrieved November 23, 2003 from: http://csalt.lancs.ac.uk/jisc/advice.htm

Chadibe, I. A. (2002). Case Study Examining The Extent To Which Urban And Semi-Rural Learning Centres Are Used As Support Systems For Distance Education Learners. UNISA, Pretoria. Retrieved November 23,2003 from: www.col.org

Conrad, D. (2002). Deep in the hearts of learners: Insights into the nature of online community, Journal of Distance Education, 17(1). Retrieved November 23, 2003 from: http://cade.athabascau.ca/vol17.1/conrad.html

Corry, N., and Lelliot, T. (2003). Supporting the Masses? Learner Perceptions Of A South African ODL Programme. In A. Tait and R. Mills (Eds.) Rethinking Learner Support in Distance Education: Change and continuity in an international context. London: Routledge.

Facey, E. (2001). First Nations and Education by Internet: The Path Forward or Back? Journal of Distance Education, 16(1). Retrieved November 23, 2003 from: http://cade.athabascau.ca/vol16.1/facey.html

Gibbs, G., and Simpson, C. (2002). How Assessment Influences Student Learning: A conceptual overview. SSRG, 42/2002, Student Support Research Group, Centre for Higher 
Education Practice, Open University UK. Retrieved November 23, 2003 from: http://cehep.open.ac.uk/cehep/ssrg/projects/index.htm

Gibbs, G. (2002). Evaluating the impact of formative assessment on student learning behaviour. Paper presented at European Association for Learning and Instruction Assessment Conference, Newcastle, August.

Goodfellow, R. (1999). Expert, Assessor, Co-Learner: conflicting roles and expanding workload for the online teacher. CAL99. Retrieved November 23, 2003 from: http://wwwiet.open.ac.uk/pp/ r.goodfellow/CAL99/cal99.html

Higgison, C. A., and Harris, R. A. (2002). Online Tutoring. The OTIS Experience: a JISC guide for online tutors. New York: TechLearn. Retrieved November 2003 from: www.techlearn.ac.uk/NewDocs/Higgison\%20D3.doc

Leach, J. (1999). Learning in Practice: Support for Professional Development. In A. Tait and R. Mills, (Eds.) Supporting the Learning in Open and Distance Learning. New York: Routledge.

Lentell, H. (2003). The Importance of the Tutor. In A. Tait and R. Mills, (Eds.) Open and Distance Learning in Rethinking Learner Support in Distance Education: Change and continuity in an international context. Routledge: London.

Li, Yawan, and Li, Linshu (2003). Construct Learning Support System for Distance Education in China. Paper presented at 10th Cambridge International Conference on Open and Distance Learning. September. Madingley Hall, Cambridge, UK.

Mason, R. (1999). IET's Masters in Open and Distance Education: What have we learned? Retrieved November 23, 2003 from: http://iet.open.ac.uk/pp/r.d.mason/MAEval.PDF

Mason, R., and Weller, M. (2000). Factors Affecting Students' Satisfaction on a Web course. Australian Journal of Educational Technology, 16(2). Retrieved November 23, 2003 from: http://www.ascilite.org.au/ajet/ajet16/mason.html

Mason, R. (2003). Online learning and supporting students: new possibilities. In A. Tait and R. Mills (Eds.) Rethinking Learner Support in Distance Education: Change and Continuity in an International Context. London: Routledge.

Mills, R. (1999). Diversity, convergence, and the evolution of student support in higher education in the UK. In A. Tait and R. Mills (Eds.) The Convergence of Distance and Conventional Education: Patterns of Flexibility for the Individual Learner. New York: Routledge.

Nonyongo, E. (2003). Changing Entrenched Learner Support Systems. In A. Tait and R. Mills (Eds.) Rethinking Learner Support in Distance Education, Change and Continuity in an International Context. London: Routledge.

Rumble, G. (1997). The Costs and Economics of Open and Distance Education. London: Kogan Page. 
SAIDE, (1998) Supporting Distance Learners: A Tutor's Guide. Capetown, SA: Francolin.

Sewart, D. (n.d). Continuity of Concern for Students in a System of Learning at a Distance. Mimeo Document. Open University UK.

Spronk, B. (1995). Appropriate Learning Technologies: Aboriginal learners, needs, and practices. In J. Roberts and E. Keough. Why the Information Highway: Lessons from Open and Distance Learning. Toronto: Trifolium.

Student Support Research Group (2002). Student Vulnerability and Retention Project: Interim Evaluation Report. Retrieved November 23, 2003 from: http://cehep.open.ac.uk/cehep/ ssrg/projects/index.htm

Student Support Research Group (2003). The financial case for a comprehensive proactive regionally based student support system. SSRG 802003. Retrieved November 23, 2003 from: http://cehep.open.ac.uk/cehep/ssrg/projects/index.htm

Tait, A. (1996). Conversation and Community. In R. Mills and A. Tait (Eds.) Supporting the Learner in Open and Distance Learning. London: Pitman Publishing.

Tait, A. (2000). Planning Student Support for Open and Distance Learning , Open Learning, 15(3) $287-299$.

World Bank (2002). Enhancing Learning Opportunities in Africa: Distance education and information and communication technologies for learning. Retrieved November 23, 2003 from: http://www-wds.worldbank.org/ servlet/WDSContentServer/WDSP/IB/2002/05 /14/000094946 02043004023268/Rendered/PDF/multi0page.pdf

\section{WORKSHOPS: Tutoring in large numbers in ODL}

\section{Appendix 1}

\section{Scenario 1: Community College in the Caribbean}

You are a lecturer in a community college in "Juan" in the Caribbean. Your college is the only public provider on Juan of advanced study that enables students to obtain the qualifications for university entrance. The Caribbean Governments' have set a target to increase the numbers of appropriately qualified applicants for university and ODL has been seen as a strategy that can significantly help achieve this target.

Your college has in the last three years stopped teaching UK syllabuses and has adopted the Caribbean Examinations Council (CXC) Advance Proficiency Examinations. This was a major challenge for staff at the college and in truth has not been universally popular. CXC has developed ODL (paper based) self study materials in a number of subjects as a pilot. Your college is also a pilot college, and your subject is one of the pilot subjects. This means at least for the forthcoming academic year all students will receive these CXC materials free. Whilst your 
college has some adult education classes, the typical student studying full time is in the 16 to 18 year range.

You do not know much about ODL, but you are very keen to help your students. A typical class of yours starts out at the beginning of the academic year with over 100 students on the register. Although you hate this - you have to admit that you are pleased that drop-out is large, because you cannot support these large numbers and because there is a wide ability range. The college has classrooms, which with a tight squeeze can accommodate these large numbers - but not all learners will have a seat. There is little in the way of reliable audio-visual equipment in the college and even for that you have to book it so far in advance that it is frequently more trouble than it is worth. All classrooms are equipped with a blackboard and chalks. There is a college library - but it is very under equipped, but it does provide some extra study support areas, and your Principal and her Senior Management team have promised to allocate classroom space for self-study with the introduction of ODL. Although, when you did your teacher training you were introduced to other teaching methods the realities you face has pushed you into a transmission mode of teaching - i.e., you lecture. You know that frequently you are not a very stimulating lecturer and you are very troubled by the poor performance of your students in the public examinations. At the moment your classes are organized around a class contact time of 20 hours per class, and you have five hours of preparation time. These hours will not change with the introduction of ODL. But you have been given complete autonomy about how you organize your teaching within the 20 hours of class contact.

TASK: You have a month before the academic year starts. And you are planning your teaching. What are you going to do?

\section{Questions to consider:}

1. What are the most significant challenges in providing responsive tutoring support to your learners?

2. What resources are available to help you fulfil your role as a tutor, and how can you make the best use of these resources?

3. What tutoring strategies (including classroom management strategies) can you use that will enable learners to benefit from peer support and group learning?

4. How can you provide personalized feedback to each learner?

5. What assessment strategies would you use during the course, and what strategies would you recommend for end-of-course assessment of learners?

6. How will each of the tutoring and assessment strategies you have identified help learners to develop study skills and their knowledge of the subject. 


\section{Appendix 2}

\section{Scenario 2: Study Centre in West Africa}

You are a tutor for your subject at the study centre in the province of "Hope," for the Open University of Misson (OUM), a country in West Africa.

OUM is a new institution based in the capital and still developing its systems. Currently the University is organized around its study centres. There is one study centre in each provincial capital, where course materials are distributed, assignments handed in and so forth. Study materials arrive at the study centres in a big truck, which brings them from the capital where OUM head office and print shop is. Sometimes there are not sufficient copies of course materials for all the learners - but last year (your first year with the university and the first year of operation of the university) students managed by sharing and copying. But there was always uncertainty that the materials would arrive in time. The materials are produced on a batch system, approximately printing a quarter of the course at a time. This is because the university does not have sufficient capacity or warehousing to produce course materials in advance, and last year much of the material was not ready. This has meant that sometimes the materials are not available when needed by students. You are not confident that this year it will be sorted as the university still has problems with warehousing and distribution.

There are five tutors including you covering your subject at your study centre; and based on last year you can expect there to be approximately 325 students following your subject at Hope Study Centre this year. Your fellow tutors, like you, are part time, and are largely involved in OUM for the money for they cannot earn sufficient from their full time post. Like you, your fellow tutors are high school teachers, and one works in the local university. However, you suspect they, like you, have thoroughly enjoyed their first year despite all the difficulties because the learners are positive and the study centre has become quite a social venue.

Although students are nominally attached to a tutor so that each tutor has a student group, numbers are always uncertain and you have never been sure which students are actually "active" on your list given to you at the beginning of the year. Moreover when you hold study centre sessions you are sure that some of the students present are not on your list. You are running tutorial sessions at the same study centre at the same time as your fellow tutors on the same course. Apart from running two tutorial sessions a month you are contracted to mark and give feedback on the assignments of your students. Last year, you had 65 learners, which meant you were marking as many 650 assignments over the 10-month course, and you expect similar numbers this year. You are finding this a major challenge - but you are paid on a piece rate system so there is some incentive to tutor large numbers.

The study centre is open all day and all evening seven days a week, and serves some 4,500 students in the region. (2000 registered in year one of operation and 2500 registered for the second year.) The study centre has four tutorial rooms and a room with six Internet connected PCs. There is a study centre organizer who is responsible for the building and has some administrative duties: room booking, etc. There is also a part time clerical officer. The electricity supply is uncertain, but this year OUM supplied the study centre with its own generator so this will improve the situation. At the moment OUM has five faculties - Arts; Education and Social Science; Maths and Computing; Science and Technology; and Business Studies. One day a week is a faculty day and last year your faculty started to put on once monthly day schools at the weekend at study centres across the country. These were very popular because, as there is only 
one study centre in each province, students have to travel a long way to get to the study centre. So for those students not living in the provincial capital, evening classes are not really viable.

After the first year of operation the university decided to appoint lead tutors for each subject taught at each study centre. You have been asked to take on the lead tutor role for your subject area at your study centre. The idea of this role is to allow some local and subject autonomy in organizing the teaching and to create a process for communication between tutors and the university administration. So your new role is essentially how to make the tutorial subject support for learners on your subject better in year two, in cooperation with your fellow subject tutors at your study centre.

\section{Appendix 3}

\section{Scenario 3: College of the Islands}

You are the tutor organizer at the College of the Islands. You appoint tutors, timetable tutorial sessions and organize the widely dispersed group of part time tutors employed by the College of the Islands. You are responsible for induction and staff development. College of the Islands is the tertiary college servicing the 15 small island states of the Pacific. There are five indigenous languages, although all teaching at your college is done in English. The College of the Islands has three college campuses, one in each of the three larger islands, but although this three campus operation is a political necessity it often means things are less efficient because communication systems between the islands are not well developed and off necessity there is a lot of duplication of effort. The student population of the College of the Islands is very diverse and geographically isolated. Some island communities can only be accessed by light aircraft. The college has offered a limited number of sub degree courses following syllabuses from overseas examination bodies for many years and has built up a solid reputation based on mixing methods and technologies print, and in particular radio. Although tutorials are available at each of the college's campuses on a twice-monthly basis attendance is poor, even from the students who live on that island. One recent innovation was the introduction of a mobile tutor team with the objective of visiting each of the smaller islands twice a year. This had some success. You know that the critical issue is learner support and without deepening this, the college will fail most of the communities it has been set up to serve.

A new innovation for this forthcoming academic year is a course on "Care in the Community". It is a diploma level course developed and accredited by the Oceana University in Australia. This course acts as the common foundation year of a degree course in the caring professions (e.g., health and social services) and is a professional course for those currently working in the field but without appropriate qualifications. This is a very significant development for the college - and everyone is looking to see how it will work out. Each module or course is designed around a core text and a wrap around study guide to the text. These materials are fairly competently done but do not take account of the culture or circumstances of the islands because they were not written for these communities. Nor in the production of these materials has there been any recognition of the learner support needed for successful ODL study. The projected student numbers suggest that in the first year the college may enrol between 40 - 50 learners, but the potential for future years is much greater. This ratio of 1:50 is within the accepted tutor student ratio operating in the college. Students will be from all the island states and even if they are from the same island they may not live in easy proximity to each other. You have been able to identify three potential tutors; all are 
working professionally in the field, and each one lives on one of the three main islands. This has pleased you because you had been worried about finding suitably qualified tutors. The College has also been given funds from an international development agency to assist in the first year of introducing this course. What are you going to do?

\section{Appendix 4}

\section{Scenario 4: GREEN}

GREEN is an international organisation that provides learning opportunities for people whose work involves advocacy for environmental issues. The people that GREEN serves are in responsible positions; in government, in corporations, in media, or in non-government agencies, and are located throughout the world. Many of them are in countries with limited resources and technologies, and typically have multiple responsibilities to work, family and their communities. They all begin their connection with GREEN when they take part in an initial learning programme that includes intensive face to face meetings and a great deal of collaborative work. As a result, each cohort of GREEN graduates tends to continue their connections with their colleagues and with GREEN staff.

Some of GREEN's training is offered as self-study modules, either in print or on CD ROMs. However, people using these modules have consistently said that they would like to have a more in-depth learning experience and receive feedback on their work that goes beyond the suggested answers provided in the modules. GREEN provided tutoring for one pilot course, but found that it was not cost-effective, because of the amount of tutoring time required to provide detailed feedback to learners.

Now GREEN is ready to test another approach; enrolling large numbers (about 60 to 80 people) in a paced 20-week course that will combine the use of the CD ROM, a moderated computer conference, and tutorial support. All participants will have their own copy of the CD and Internet access, although in some cases their Internet access is intermittent. GREEN staff will manage enrolment of learners and distribution of materials, and will do some screening to ensure prospective participants have the appropriate background and adequate computer access. The course design requires every participant to work on a project throughout the course and to submit it for a mid-course review and for a final assessment.

You have been selected as the sole tutor for this course. Your responsibilities will be to provide support for participants so that they can each prepare a project that is appropriate for their own needs and for their context; to enable participants to support and learn from each other; and to ensure that each participants' project receives detailed and helpful feedback. You have tutored or facilitated e-learning situations before, but have always dealt with relatively small numbers of people who are from similar contexts and share similar values. You know that the strategies you've used for smaller numbers and more homogeneous groups won't necessarily be effective for a large, diverse group. 


\section{Appendix 5}

\section{Scenario 5: Seaforth College}

You are a tutor at Seaforth College in the UK on a foundation law course. Seaforth is a small charitable trust that was set up after the Second World War to provide education and training opportunities for de mobbed troops who were unable to study full time. Seaforth College pioneered part-time distance education utilizing correspondence methods. There are no-face-to face meetings for students, and on its core courses there is no student - student interaction, all interaction is between the tutor and the student conducted at a distance. Moreover the college is committed to openness by which it means students are free to register, and study at their own time and pace. They do not study in a "lock-step" fashion. Seaforth College's uniqueness stems from it being a "not for profit" provider of tutorial services. That is it provides a tutorial service for the courses/syllabuses of other providers. The college in some instances creates the student study materials that underpin the syllabuses of these providers. The Government does not fund Seaforth College; its only income is from the fees its students' pay. The college's significant reputation has been earned from its high standards of learner materials for British secondary school examinations - both the general and advanced syllabuses. The college is now providing very successfully study materials and tutor services for a range of occupational and professional qualifications, and is pioneering work based learning. The college is also positioning itself to move into a completely electronic environment with its own managed learning environment.

You are a tutor on what used to be a very significant area of the College's provision - namely support for the London University External Programme. You know that the college continues to provide a service here even though it just about covers its costs. Learners pay a registration fee that entitles them to an initial contact with you (phone, fax, or email) the purpose of which is to design a tailor - made study programme, and five assignment forms. An assignment form accompanies a students' submitted assignment. The assignment was set by you at the initial contact session or after the previous assignment was handed in. Students are essentially having one-to-one tutorial sessions at a distance with you after the submission of a piece of work. The only pacing that is provided is the London external examinations that are held once a year and students have to decide if they are going to enter the exams that year some months before. London University does not provide any study materials, but it does provide a syllabus and an extensive reading list.

You have for a number of years questioned why you continue with this tutoring, as it is certainly not financially worthwhile. But over the years you have had very rewarding relationships with your students, who are largely overseas, and for all of them this is the only way of getting higher education. Some of your past students have risen to high office in their countries, and a number have won University of London awards for the best student in the year - including on campus students.

At anyone time you have approximately 18-20 students attached to you, but they are all at different stages in their studies. If a student does not submit any work for two years, the college deems them to be dormant and they are removed from your list. You have known students become active again after "rests" of eight years. There is a high drop our rate on these programmes - learners stop submitting assignments even though they may have purchased assignment forms. The successful learners are very committed, and self motivated. You often think of them as auto-didacts. 
Task: The College has given you authority to reorganize your tutorial provision. What will you do to ensure that your time is used more effectively and tutorial provision is improved?

\section{Questions to consider:}

1. What are the challenges you face?

2. What resources are available to you?

3. What strategies could you use to achieve economies of scale in this customerised tutoring situation?

\section{Appendix 6}

\section{Scenario 6: Accounting}

You are a general accountant in a medium-sized city in the United Kingdom, and for some years, you have been tutoring people who are preparing for their certification exams. You are contracted by a local college to provide this tutoring service for people who have successfully completed and passed all their accountancy courses, but must pass two comprehensive exams, (a general one and one in their field of specialisation) in order to receive their professional certification. The college does not offer any face-to-face classes to those preparing for these exams; instead, it contracts with local accountants to provide individual tutoring. In your community, you are the only accountant taking on this work, but there are two or three other accountants in nearby cities who are also tutors. As well, since the exams are offered nationally, there are tutors across the country, most of them contracted by local colleges.

Opportunities to sit these exams are offered by the professional accountancy organisation twice a year, and candidates usually begin their preparation, either on their own or with tutorial help, about four months in advance of the exam date. You usually tutor about 20 candidates at a time, and help them prepare both for the general exam and for any one of five specialised exams. It is interesting work, but it means that you have to customise your tutoring for each person, because everyone has quite different levels of preparedness, and each person is also studying for a specialisation. Because the exams test learners' problem-solving abilities, most of your tutoring involves commenting on learners' assignments, which are based on previous exam questions and case studies. You do all your tutoring by email.

As you are nearing retirement, you would like to be able to increase the number of people you tutor to about 50 at a time, so that you can use this activity to supplement your income. (The college pays you a base rate according the number of students you have, plus a set fee for each assignment you mark.) You have developed some resource materials to help your learners; the college has copies of previous exams, and the professional accountancy organisation provides a handbook for candidates explaining the general principles of the qualifying exams. You are wondering how you can make your tutoring more efficient so that you can manage to work with up to 50 candidates at a time. What would you recommend? 


\section{Appendix 7}

\section{Scenario 7: SARS}

You are an instructor in a university school of medicine in Eastern Canada and your area of specialisation is infection control. You are a qualified nurse with a graduate degree and advanced training in microbiology and in infection control. Although medical students and nurses are usually very conscientious learners about your subject, you are sometimes frustrated that doctors do not always practice effective infection control. This is partly the result of an attitude that doctors are too busy and too crucial to the system to pay attention to all these detailed rules and procedures. However, the recent SARS outbreak worldwide has prompted the Ministry of Health to require new, more rigorous infection control precautions, and all hospital staff must complete training in these precautions within the next six months, so they are prepared for the next SARS outbreak.

Your university has prepared a distance course to provide this training, and you will be one of two tutors responsible for a group of 400 doctors at two teaching hospitals affiliated with your university. Even though participants are local, their busy schedules make it impossible to attend face-to-face classes. The course is designed to be as flexible as possible. It requires about 20 hours of study time over the two-month course duration. A CD provides the essential information, but as a tutor, you are responsible for ensuring that everyone has mastered it. As well, you know that your role involves changing attitudes among doctors so that they all take infection control seriously and follow the new protocol. The course material provides adequate data and good rationales to support the change in behaviour, and also encourages participants to form learning groups and engage in computer-mediated discussions so that they can raise questions and issues. You would like to use these discussions to draw out any objections or concerns about the new procedures so that these can be addressed, and participants will be more likely to apply these procedures in their practice. As well, you have to work out how to ensure that participants have in fact acquired the skills, knowledge and commitment to use the new procedures.

\section{Appendix 8}

\section{Scenario 8: Leather Industry in India}

The Government of India has identified the need to upgrade skills in tannery workers to propel the Indian Leather industry into the 21st Century. The formal education system was unable to meet this need because: the target group were in the work force, the numbers to be trained were very large (1.4 million), the areas to be trained were not covered by formal systems, learners were distributed geographically through various tanneries in the country, each tannery had needs specific to local requirements, educational background of learners varied drastically from graduate to illiterate and tanneries find it difficult to spare workers for training.

A national open university has developed a 20-week course, which is competency based, is work based and uses open learning and distance education methodologies. Strong partnerships have been established between the experts at the university and experts in the leather industry to develop and implement the programme. In order to cater for the varied educational backgrounds of learners - including range of languages - the entire course was produced in both print and on audiotape. Learners are assessed during the 20 week course on their practical competencies in a number of areas covered by the programme. 
The delivery system provides learner support through work based demonstration and training at the worker's tannery; and supplementary support, general guidance and assistance at study centers located in the tannery or in partnering institutions located in the community.

The course was introduced in March 1999, and all the feedback suggests that workers are showing strong motivation to undertake and pursue the training. The course has been praised internationally and nationally for providing a model of how flexible delivery methods can meet training needs and for showing the importance of a strong culture of partnerships involving government, training institutions and enterprises.

You are a worker trainer on the Tannery Training Programme. You work in a large leather factory and have been given remittance of eight hours for your duties of supporting 30 learners on the programme, half of which are for direct class contact. The other half of your time is for assessment, record keeping (recording marks), and individual or small group work where possible. The work-based training is on the job training and is very much in the hands of the managers of the different areas. Your training input is designed to supplement the work-based training. Although enabling employees to participate in the programme is company policy, in reality the ability of a worker to participate is determined by their foremen - are they supportive of the programme and an individual learner or not. So sometimes individual learner attendance is erratic. The room provided for the study center is very basic with little or no equipment but you do have sufficient copies of the learner materials for each learner. You also have a very mixed group with respect to educational abilities. The materials take "one-size" fits all approach, which is taxing given the wide range of abilities reflected in your group. In the early years of the course student motivation was indeed high but you have found that this is declining because promised wage increases and promotion for graduates of the programme that applied in the first years of the programme, no longer seem to be materializing. You are concerned about this. You are one of seven worker trainers in the factory. You do not meet other trainers because you each use the study center on different days. Although you are committed to the ideas behind the programme you are becoming a bit de motivated too. How can you restore your own motivation and that of your learners?

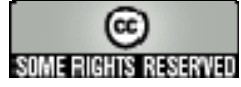

